OPEN ACCESS

Edited by:

Stefano Zucchini,

Sant'Orsola-Malpighi Polyclinic, Italy

Reviewed by:

Maurizio Delvecchio,

Giovanni XXIII Children's Hospital, Italy

Giorgio Radetti,

Ospedale di Bolzano, Italy

*Correspondence:

Saartje Straetemans

saartje.straetemans@mumc.n

${ }^{\dagger}$ These authors have contributed equally to this work and share

senior authorship

Specialty section: This article was submitted to

Pediatric Endocrinology,

a section of the journal

Frontiers in Endocrinology

Received: 08 March 2021

Accepted: 10 May 2021

Published: 01 June 2021

Citation:

Straetemans S, Rooman $R$ and De Schepper J (2021) Is a Two-Year

Growth Response to Growth Hormone Treatment a Better Predictor of Poor Adult Height Outcome Than a

First-Year Growth Response in

Prepubertal Children With Growth Hormone Deficiency?

Front. Endocrinol. 12:678094. doi: 10.3389/fendo.2021.678094

\section{Is a Two-Year Growth Response to Growth Hormone Treatment a Better Predictor of Poor Adult Height Outcome Than a First-Year Growth Response in Prepubertal Children With Growth Hormone Deficiency?}

\author{
Saartje Straetemans ${ }^{1,2,3^{*}}$, Raoul Rooman ${ }^{4 \dagger}$ and Jean De Schepper ${ }^{3,5,6 t}$ \\ on behalf of BESPEED ${ }^{3}$
}

1 Department of Pediatric Endocrinology, Maastricht University Medical Center, Maastricht, Netherlands, ${ }^{2}$ NUTRIM School of Nutrition and Translational Research in Metabolism, Maastricht University, Putte, Netherlands, ${ }^{3}$ The BElgian Society for PEdiatric Endocrinology and Diabetology (BESPEED), Brussels, Belgium, ${ }^{4}$ PendoCon bv, Putte, Belgium, ${ }^{5}$ Department of Pediatric Endocrinology, University Hospital Brussels, Brussels, Belgium, ${ }^{6}$ Department of Pediatric Endocrinology, University Hospital Ghent, Ghent, Belgium

Objective: The first year response to growth hormone $(\mathrm{GH})$ treatment is related to the total height gain in $\mathrm{GH}$ treated children, but an individual poor first year response is a weak predictor of a poor total GH effect in GH deficient (GHD) children. We investigated whether an underwhelming growth response after 2 years might be a better predictor of poor adult height (AH) outcome after GH treatment in GHD children.

Design and methods: Height data of GHD children treated with GH for at least 4 consecutive years of which at least two prepubertal and who attained (near) (n)AH were retrieved from the Belgian Register for $\mathrm{GH}$ treated children ( $n=110,63 \%$ boys). In ROC analyses, the change in height $(\Delta \mathrm{Ht}) \mathrm{SDS}$ after the first and second $\mathrm{GH}$ treatment years were tested as predictors of poor AH outcome defined as: (1) nAH SDS $<-2.0$, or (2) nAH SDS minus mid-parental height SDS $<-1.3$, or (3) total $\Delta \mathrm{Ht}$ SDS $<1.0$. The cut-offs for $\Delta \mathrm{Ht}$ SDS and its sensitivity at a 95\% specificity level to detect poor AH outcome were determined.

Results: Eleven percent of the cohort had a total $\Delta \mathrm{Ht} \mathrm{SDS}<1.0$. ROC curve testing of first and second years $\Delta \mathrm{Ht}$ SDS as a predictor for total $\Delta \mathrm{Ht}$ SDS $<1.0$ had an $\mathrm{AUC}>70 \%$. Firstyear $\Delta \mathrm{Ht}$ SDS $<0.41$ correctly identified $42 \%$ of the patients with poor $\mathrm{AH}$ outcome at a 95\% specificity level, resulting in respectively 5/12 (4.6\%) correctly identified poor final responders and 5/98 (4.5\%) misclassified good final responders (ratio 1.0). $\Delta \mathrm{Ht}$ SDS after 2 prepubertal years had a cut-off level of 0.65 and a sensitivity of $50 \%$ at a $95 \%$ specificity 
level, resulting in respectively 6/12 (5.5\%) correctly identified poor final responders and 5/ 98 (4.5\%) misclassified good final responders (ratio 1.2).

Conclusion: In GHD children the growth response after 2 prepubertal years of GH treatment did not meaningfully improve the prediction of poor $\mathrm{AH}$ outcome after $\mathrm{GH}$ treatment compared to first-year growth response parameters. Therefore, the decision to re-evaluate the diagnosis or adapt the GH dose in case of poor response after 1 year should not be postponed for another year.

Keywords: growth hormone treatment, growth hormone deficiency, children, growth response, poor adult height outcome

\section{INTRODUCTION}

The goal of growth hormone (GH) treatment in a GH deficient (GHD) child is to attain a true catch-up growth, resulting in an adult height $(\mathrm{AH})$ close to target height (1). The pattern of $\mathrm{GH}$ induced growth consists of a first phase of accelerated growth, which allows the child to approach its target height in a number of years and is followed by a phase of maintenance growth where height velocity $(\mathrm{HV})$ is normal. Several studies have evidenced that this $\mathrm{GH}$ induced growth acceleration diminishes rapidly, which is called the waning effect $(2,3)$. This waning has been explained by a $\mathrm{GH}$ receptor desensitization, but its determinants have been poorly studied in children with GHD.

In clinical practice, the first-year growth response is most often used to evaluate the individual response to $\mathrm{GH}$ treatment $(4,5)$, allowing the early identification of GHD patients who may not respond to a physiological GH replacement and/or are not GHD. However, we recently showed that the currently used first-year growth response and responsiveness parameters have a low sensitivity and/or specificity to predict a suboptimal adult height outcome after long-term GH treatment in prepubertal GHD children (6).

Many issues may negatively influence the first year response to $\mathrm{GH}$ treatment, including $\mathrm{GH}$ injection problems, an inappropriate $\mathrm{GH}$ starting dose, a hidden growth limiting disease, or additional hormonal deficiencies appearing during $\mathrm{GH}$ therapy (e.g. central hypothyroidism) (7). Correction of these conditions in the second year may result in an improved linear growth during the second year. In addition, a less pronounced waning effect in the second year of GH treatment might also explain why some children with an inadequate firstyear growth response do have an adequate $\mathrm{AH}$ outcome.

We therefore investigated in prepubertal children with a nonorganic GHD: 1) the contribution of the first 2 years of GH therapy to the total height increase, 2) the magnitude and determinants of the waning of the growth response during the second year, and 3) the eventual improvement of poor adult height prediction after two years of GH therapy in comparison with the prediction after one year of $\mathrm{GH}$ treatment. We hypothesized that the growth response after 2 years of GH treatment may be a better predictor of poor adult height outcome than the first year response, as in some patients a less pronounced waning in the second year might compensate a failing first year growth response to GH therapy.

\section{MATERIALS AND METHODS}

\section{Materials}

The auxological data and GH treatment characteristics of children diagnosed with GHD, collected by the members of the BElgian Society for PEdiatric Endocrinology and Diabetology (BESPEED) in a national database, called Belgrow, since 1986 were retrieved. This study was approved by the ethical committee of Brussels Free University and the University Hospital Brussels in Belgium. All subjects gave written informed consent in accordance with the Declaration of Helsinki. In the registry, all data are pseudonymized to comply with rigorous privacy guidelines. Only patients who had been treated exclusively with daily recombinant human $\mathrm{GH}$ for at least 4 consecutive years of which at least two were prepubertal and who had attained (near) $\mathrm{AH}(\mathrm{nAH})$ were included. The patients were mostly treated in a time period when the dose for GHD in Belgium was fixed to $25 \mathrm{mcg} / \mathrm{kg}$ * day. GHD patients with central malformations (e.g. anomalies of the pituitary and/or stalk) and patients with idiopathic GHD as well as patients with congenital GHD related to genetic alterations (e.g. GH gene mutations) were included, but those with acquired GHD of known cause (related to e.g. a brain tumor, brain irradiation, brain trauma) were excluded. Other exclusion criteria were any medication or known medical condition other than GHD that could affect growth, interruption of $\mathrm{GH}$ treatment for more than 6 months, and a birth weight and/or birth length below -2 SD. Girls aged $\geq 12$ years and boys aged $\geq 13$ years at the end of the second GH treatment year were excluded. In total, 110 patients (69 males and 41 females) with non-acquired GHD (66 with isolated GHD and 44 with multiple pituitary hormone deficiency) met the inclusion and exclusion criteria.

\section{Methods}

The diagnosis of GHD was made by the treating physician and peer-reviewed by BESPEED members (8). All patients had a peak $\mathrm{GH}$ concentration of $<10 \mu \mathrm{g} / \mathrm{L}$ after both glucagon and insulin stimulation. Pubertal onset was defined as testicular volumes $\geq 4 \mathrm{ml}$ for boys and Tanner breast stage $\geq 2$ in girls.

Birth weight for gestational age was transformed into SDS, based on the standards of Niklasson et al. (9). The MPH was calculated according to Tanner et al. as follows: (father's height + mother's height +13 for boys/-13 for girls)/2 (10). Height, weight, BMI, and MPH were converted to SDS using Flemish reference data (11). 
$\mathrm{nAH}$ was defined as the height attained when $\mathrm{HV}$ was less than $2 \mathrm{~cm}$ /year, calculated over a period of minimum 9 months, and chronological age $>17$ years in boys and $>15$ years in girls. nAH SDS was calculated in two different ways, using the Flemish reference data: (1) for the chronological age (CA), (2) for an age of 21 years (A21).

The change in height $(\Delta \mathrm{Ht})$ SDS was calculated after the first and second prepubertal year of GH therapy, provided that the height data were available within a 9-15 month interval for that year and scaled to respectively 12 and 24 months.

The final outcome of the GH treatment was evaluated by three different methods: (1) nAH, expressed as a height SDS; (2) total $\triangle \mathrm{Ht}$ SDS, calculated as the nAH SDS minus height SDS at start of GH treatment; (3) nAH SDS minus midparental height $(\mathrm{MPH}) \mathrm{SDS}$, an index of achieving the genetic height potential. A poor final treatment outcome was defined as total $\Delta \mathrm{Ht} \operatorname{SDS}<1.0$, nAH SDS - MPH SDS $<-1.3$, and nAH SDS $<-2.0$

Receiver operating characteristic (ROC) curve analyses were performed for $\Delta \mathrm{Ht}$ SDS after the first and second prepubertal years as a predictor for the defined poor adult height outcome parameters. We have previously published the results of ROC analyses of the first year only, in a cohort overlapping the cohort of this study (6).

\section{Statistical Analysis}

The variables are reported as the median (25-75th percentiles) and mean $( \pm S D)$. A Shapiro-Wilk test was used to test for the normal distribution. ROC curve analyses were performed to examine the relationship between sensitivity and specificity for the different test parameters and the different outcome parameters. Only pairs with an area under the ROC-curve (AUC) $\geq 70 \%$ were further analyzed. In order to misdiagnose only $5 \%$ of good responders, a specificity level of $95 \%$ was chosen to calculate the corresponding cut-off values for $\Delta \mathrm{Ht}$ SDS. Linear regression analyses were performed to study the relationship between the growth responses and possible explanatory variables. Significance was considered at the $5 \%$ level $(\mathrm{p}<$ 0.05). MedCalc ${ }^{\circledR}$ and IBM SPSS Statistics $25^{\circledR}$ software was used for all statistical analyses.

\section{RESULTS}

\section{Clinical Characteristics}

The background and auxological characteristics of 110 included GHD children (69 males, 41 females) are listed in Table 1. GH therapy was initiated at a mean age of 6.2 years and at a median height SDS of -3.47 , which was 2.47 SDS below the MPH SDS. The mean GH dose at start was $28 \mu \mathrm{g} / \mathrm{kg}$.day. The mean duration of $\mathrm{GH}$ therapy was 10.2 years, with a mean duration before pubertal onset of 6.2 years. Girls entered puberty spontaneously at a mean age of 11.3 years $(n=35)$, boys at a mean age of 12.5 years $(n=45)$. Puberty was hormonally induced at a mean age of 12.9 years in girls $(n=5)$ and 13.9 years in boys $(n=20)$. nAH was attained at a mean age of 16.7 years in girls and 18.7 years in boys.

\section{Response to GH Treatment During the First Two Years of Treatment}

The median $\Delta \mathrm{Ht}$ SDS after the first treatment year was 1.03, while the median $\Delta \mathrm{Ht}$ SDS during the second year was 0.43 (Table 1). Figure 1 shows the individual data and the correlation between $\Delta$ height SDS during the first and second GH treatment years. The $\Delta \mathrm{Ht}$ SDS during the second year correlated moderately $(\mathrm{r}=0.553$; $\mathrm{p}<0.001)$ with the first year height increase. Patients with a lower than median $\Delta \mathrm{Ht}$ SDS $(<1.03 \mathrm{SD})$ during the first treatment year had a median second year $\Delta \mathrm{Ht}$ SDS of 0.29 SD, which was 0.33 SD lower than the first year; their median $\Delta \mathrm{Ht}$ SDS after 2 years was 0.95 . In contrast, patients with a higher than median first-year $\Delta \mathrm{Ht}$ SDS $(>1.03)$ had a median second year $\Delta \mathrm{Ht}$ SDS of $0.57 \mathrm{SD}$, which was $0.77 \mathrm{SD}$ lower than the first year; their median $\Delta \mathrm{Ht}$ SDS after 2 years was 2.01. Of the 55 patients with a higher than median first-year $\Delta \mathrm{Ht}$ SDS, 19 had a lower than median second-year response (shown in quadrant D in Figure 1), while 17/55 patients with a lower than median firstyear $\Delta \mathrm{Ht}$ SDS had a higher than median second year increase (shown in quadrant A). Only 4/110 patients had a second year $\Delta \mathrm{Ht}$ SDS that was higher than the first year $\Delta \mathrm{Ht}$ SDS.

\section{Determinants of the Waning Effect During the Second Year}

The first year $\Delta \mathrm{Ht}$ SDS correlated negatively with maximum $\mathrm{GH}$ peak in the $\mathrm{GH}$ stimulation tests, age at start, height minus MPH SDS at start, height SDS at start, and correlated positively with BMI SDS at start, mid parental height SDS and GH dose at start (Table 2). Whereas the height SDS increase in the second year correlated positively with first-year $\Delta \mathrm{Ht}$ SDS and negatively with maximum GH peak, height minus MPH SDS at start, height SDS at start, and age at start. The waning effect, calculated by the difference between $\Delta H \mathrm{H}$ SDS in the second year and $\Delta \mathrm{Ht}$ SDS in the first year, was positively correlated with first-year $\Delta \mathrm{Ht}$ SDS, height SDS after the first and second years, BMI SDS at start, and correlated negatively with age at start, height minus $\mathrm{MPH}$ at start, maximum $\mathrm{GH}$ peak, and height SDS at start.

\section{Response to GH Treatment During the Whole Treatment Period}

Figure 2 compares the height SDS at start of GH treatment, after the first and second GH treatment years, at pubertal onset and at near AH. After one and two years of GH therapy, the median $\Delta \mathrm{Ht}$ SDS was respectively 1.03 and 1.44 . At onset of puberty, median $\Delta \mathrm{Ht}$ SDS was 1.80 . The median $\Delta \mathrm{Ht}$ SDS at $\mathrm{nAH}$ was 2.09 for chronological age (CA), but 1.86 when extrapolated to the age of 21 years (A21). The 2 year $\Delta H$ t SDS accounted thus for $69 \%$ (CA) $-77 \%$ (A21) of the total increase in height SDS. Twenty five percent of the patients had a $\Delta \mathrm{Ht}$ SDS $<1.0$ at 2 years, $20 \%$ at pubertal onset, and $11 \%(\mathrm{CA})-16 \%(\mathrm{~A} 21)$ at $\mathrm{nAH}$.

After two years $46 \%$ of the patients had a height SDS $<-2.0$ and $35 \%$ at pubertal onset, whereas at the moment of nAH, $25 \%$ (CA) and 28\% (A21) of the patients had a height SDS $<-2.0$. The median difference of the height SDS with the MPH SDS gradually diminished over time after the first and second 
TABLE 1 | Characteristics: background, at GH start, after $1^{\text {st }}$ year, after $2^{\text {nd }}$ year, at pubertal onset, at $n A H$.

\begin{tabular}{|c|c|c|c|c|c|c|}
\hline & $\mathbf{n}$ & median & p25 & p75 & mean & SD \\
\hline \multicolumn{7}{|l|}{ Background } \\
\hline gestational age, weeks & 104 & 40.0 & 38.0 & 40.0 & 38.5 & 2.9 \\
\hline birth weight, SDS & 103 & -0.27 & -0.77 & 0.25 & -0.18 & 0.89 \\
\hline birth length, SDS & 93 & -0.27 & -0.77 & 0.25 & -0.24 & 0.95 \\
\hline father height, SDS & 105 & -1.20 & -1.80 & -0.15 & -1.03 & 1.17 \\
\hline mother height, SDS & 105 & -0.78 & -1.62 & -0.27 & -0.91 & 1.16 \\
\hline MPH, SDS & 105 & 1.05 & -1.71 & -0.45 & -0.99 & 0.95 \\
\hline maximum GH peak, $\mu \mathrm{g} / \mathrm{L}$ & 110 & 3.9 & 2.1 & 6.7 & 4.3 & 2.7 \\
\hline \multicolumn{7}{|l|}{ at start GH treatment } \\
\hline age, years & 110 & 6.1 & 4.6 & 8.2 & 6.2 & 2.3 \\
\hline height, SDS & 110 & -3.44 & -3.99 & -2.80 & -3.47 & 0.86 \\
\hline height minus MPH, SDS & 105 & -2.44 & -3.10 & -1.75 & -2.47 & 1.11 \\
\hline BMI, SDS & 110 & -0.42 & -1.20 & 0.41 & -0.33 & 1.11 \\
\hline GH dose, $\mu \mathrm{g} / \mathrm{kg}$.day & 110 & 27.0 & 24.5 & 31.1 & 28.0 & 5.5 \\
\hline \multicolumn{7}{|l|}{ after first year GH treatment } \\
\hline height, SDS & 110 & -2.36 & -2.91 & -1.89 & -2.42 & 0.83 \\
\hline$\Delta$ height, SDS ${ }^{a}$ & 110 & 1.03 & 0.65 & 1.40 & 1.05 & 0.50 \\
\hline$\Delta$ height velocity, $\mathrm{cm} /$ year & 95 & 4.8 & 3.1 & 7.2 & 5.2 & 3.2 \\
\hline height minus MPH, SDS & 105 & -1.34 & -2.03 & -0.73 & -1.41 & 0.98 \\
\hline \multicolumn{7}{|l|}{ after second year GH treatment } \\
\hline height, SDS & 110 & -1.92 & -2.52 & -1.47 & -1.95 & 0.88 \\
\hline$\Delta$ height, SDS ${ }^{b}$ & 110 & 1.44 & 0.95 & 2.01 & 1.52 & 0.72 \\
\hline$\Delta$ height velocity, $\mathrm{cm} /$ year & 110 & -2.5 & -3.6 & -1.3 & -2.5 & 1.9 \\
\hline height minus MPH, SDS & 105 & -0.94 & -1.62 & -0.28 & -0.94 & 0.97 \\
\hline \multicolumn{7}{|l|}{ at puberty onset } \\
\hline age onset spontaneous puberty (females), years & 35 & 11.4 & 10.6 & 12.1 & 11.3 & 1.0 \\
\hline age puberty induction (females), years & 5 & 13.0 & 11.8 & 13.9 & 12.9 & 1.0 \\
\hline age onset spontaneous puberty (males), years & 45 & 12.7 & 12.0 & 13.1 & 12.5 & 1.0 \\
\hline age puberty induction (males), years & 20 & 14.0 & 13.3 & 14.2 & 13.9 & 1.2 \\
\hline duration GH therapy before puberty, years & 105 & 6.3 & 4.4 & 8.2 & 6.2 & 2.4 \\
\hline height, SDS & 104 & -1.52 & -2.29 & -0.97 & -1.52 & 1.09 \\
\hline$\Delta$ height, SDS $^{\mathrm{c}}$ & 104 & 1.80 & 1.14 & 2.65 & 1.94 & 1.03 \\
\hline height minus MPH, SDS & 99 & -0.49 & -1.27 & 0.05 & -0.52 & 1.11 \\
\hline \multicolumn{7}{|l|}{ at $\mathrm{nAH}$} \\
\hline age, years & 110 & 17.9 & 16.9 & 18.9 & 18.0 & 2.2 \\
\hline age, years (females) & 41 & 16.5 & 15.2 & 17.8 & 16.7 & 1.8 \\
\hline age, years (males) & 69 & 18.3 & 17.1 & 19.2 & 18.7 & 2.2 \\
\hline age stop GH treatment, years & 110 & 16.5 & 15.4 & 17.4 & 16.4 & 1.5 \\
\hline age stop GH treatment, years (females) & 41 & 15.2 & 14.5 & 16.5 & 15.5 & 1.4 \\
\hline age stop GH treatment, years (males) & 69 & 16.8 & 16.1 & 17.6 & 16.9 & 1.3 \\
\hline growth since stop $\mathrm{GH}$ treatment, cm & 106 & 0.5 & 0.0 & 1.2 & 1.3 & 2.5 \\
\hline duration GH therapy, years & 110 & 10.2 & 8.2 & 12.0 & 10.2 & 2.4 \\
\hline nAH CA, SDS & 110 & -1.21 & -1.97 & -0.39 & -1.21 & 1.12 \\
\hline nAH A21, SDS & 110 & -1.53 & -2.22 & -0.67 & -1.44 & 1.14 \\
\hline nAH CA minus MPH, SDS & 105 & -0.20 & -0.72 & 0.46 & -0.19 & 0.99 \\
\hline nAH A21 minus MPH, SDS & 105 & -0.42 & -0.99 & 0.22 & -0.43 & 0.98 \\
\hline$\Delta$ height (onset puberty until nAH CA), SDS & 104 & 0.26 & -0.18 & 0.81 & 0.28 & 0.26 \\
\hline$\Delta$ height (onset puberty until nAH A21), SDS & 104 & 0.02 & -0.55 & 0.71 & 0.05 & 0.84 \\
\hline total $\Delta$ height $\mathrm{CA}, \mathrm{SDS}^{\mathrm{d}}$ & 110 & 2.09 & 1.56 & 3.00 & 2.27 & 1.11 \\
\hline total $\Delta$ height $\mathrm{A} 21, \mathrm{SDS}^{\mathrm{d}}$ & 110 & 1.86 & 1.18 & 2.74 & 2.03 & 1.16 \\
\hline BMI CA, SDS & 95 & -0.11 & -1.12 & 0.65 & -0.16 & 1.33 \\
\hline BMI A21, SDS & 95 & -0.50 & -1.53 & 0.33 & -0.46 & 1.42 \\
\hline
\end{tabular}

GH, growth hormone; MPH, midparental height; BMI, body mass index; $n A H$, near adult height; SDS, standard deviation score; cm, centimeter; A21, SDS calculated at age 21 years; CA, SDS calculated at chronological age; ${ }^{a}$ gain in height SDS from start until after first-year GH treatment; ${ }^{b}$ gain in height SDS from start until after second year of GH treatment; ${ }^{\circ}$ gain in height SDS from start of GH treatment until onset puberty; ' gain in height SDS from start of GH treatment until nAH.

prepubertal years of GH treatment until pubertal onset, respectively $1.34,0.94$, and 0.49 SDS. At start, $87 \%$ of the patients had a height - MPH SDS $<-1.3$, after two years this percentage decreased to $35 \%$, and at pubertal onset it was $23 \%$ of the patients. Finally, $12 \%(\mathrm{CA})$ and $14 \%(\mathrm{~A} 21)$ of the patients had a nAH - MPH SDS $<-1.3$.

\section{Response to GH Treatment in Isolated GHD Versus MPHD}

Of 110 patients, 44 had multiple pituitary hormone deficiencies that were supplemented. $\Delta \mathrm{Ht}$ SDS after 1 year, $\Delta \mathrm{Ht}$ SDS after 2 years, and total $\Delta \mathrm{Ht}$ SDS were comparable between the group with isolated GHD and MPHD (Table 3). 


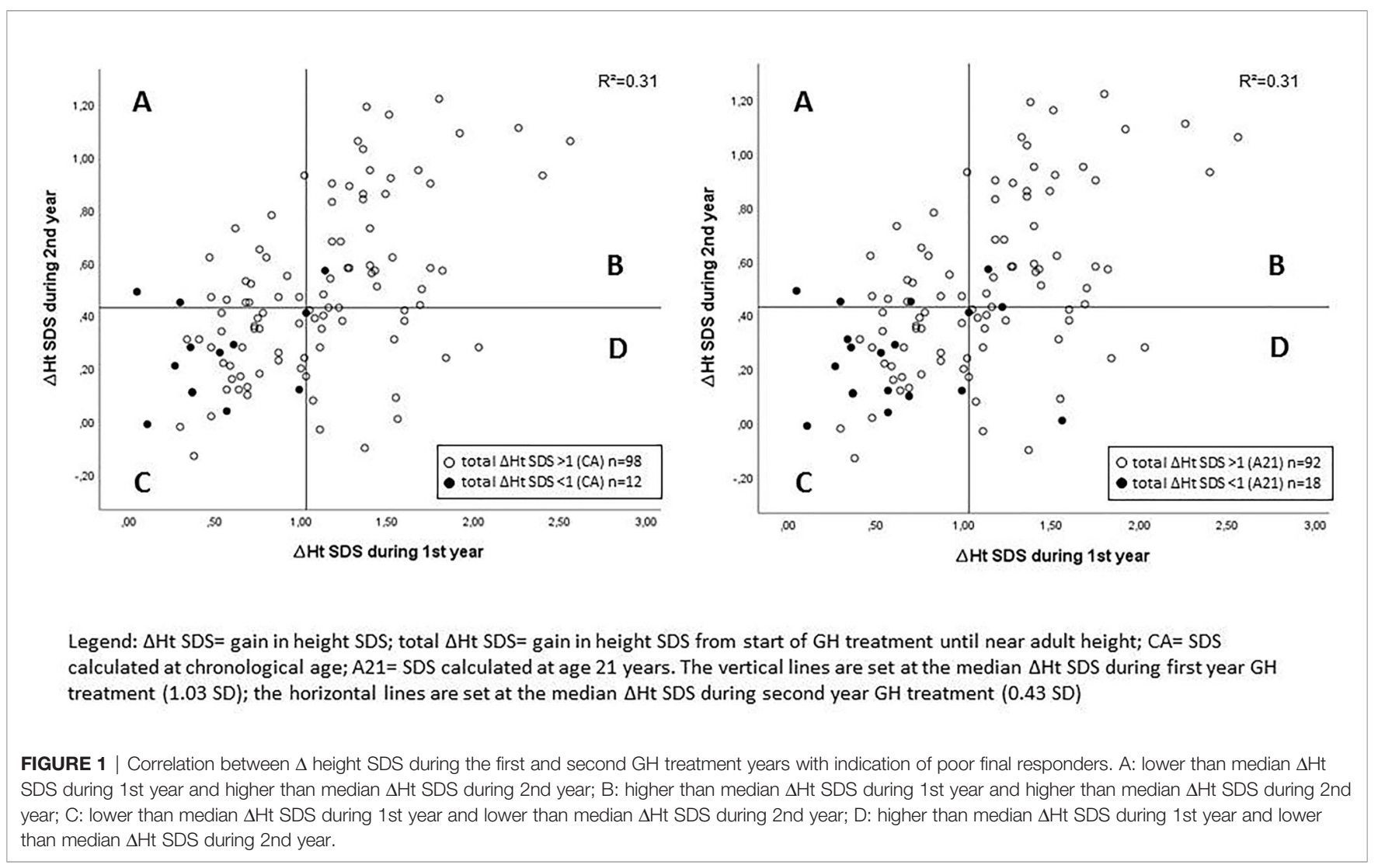

TABLE 2 | Linear regression analyses for the prediction of first and second year $\Delta \mathrm{Ht}$ SDS and the waning effect during the second GH treatment year in prepubertal GHD patients.

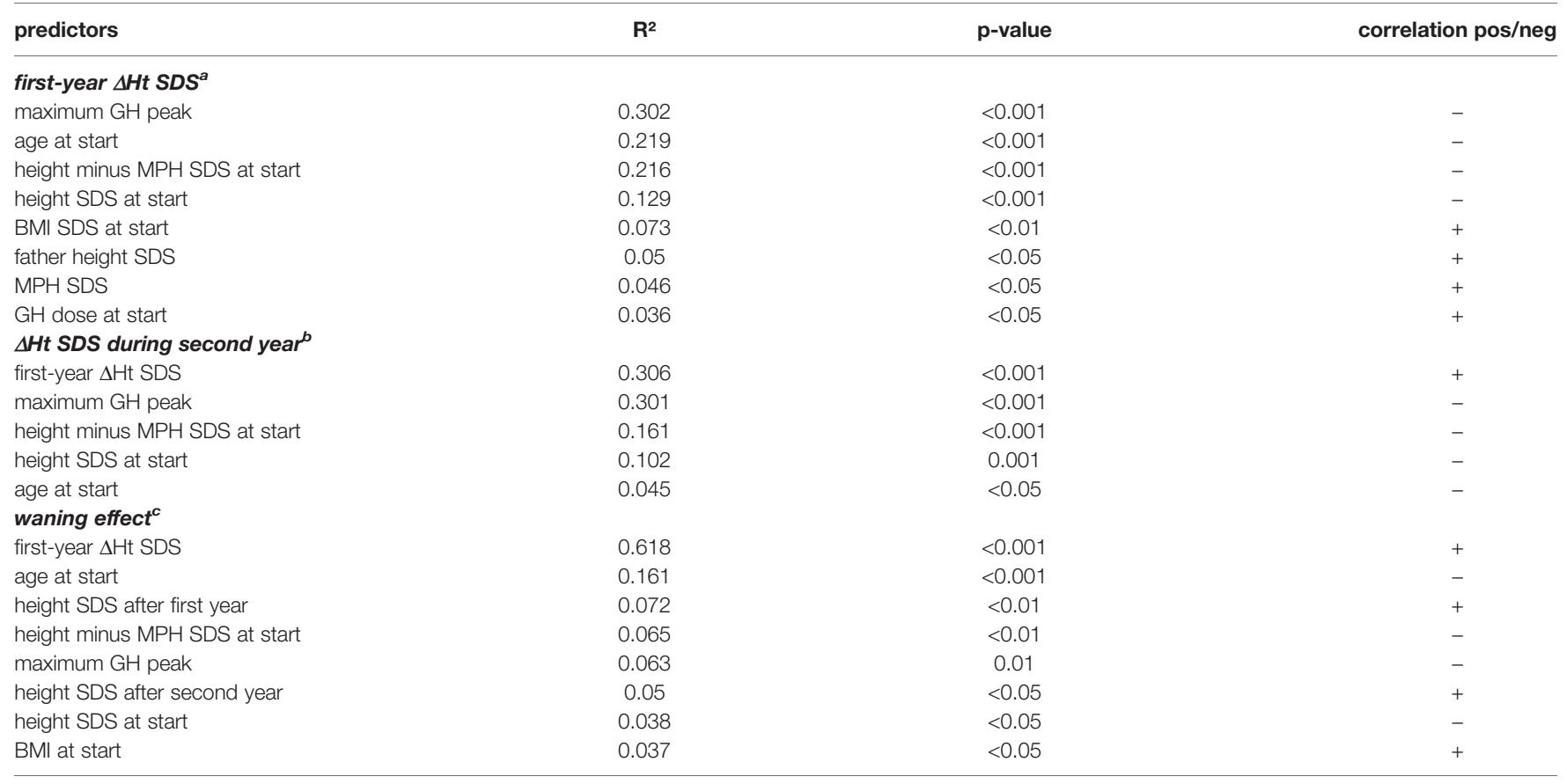

${ }^{a}$ gain in height SDS after 1 year of GH treatment; ${ }^{b}$ gain in height SDS after 2 years of GH treatment; ${ }^{c}$ waning effect, first-year $\Delta H t$ SDS minus $\Delta H t$ SDS during second year; GH, growth hormone; GHD, GH deficient; $R^{2}$, the coefficient of determination; pos, positive correlation; neg, negative correlation; MPH, mid parental height; BMI, body mass index. 


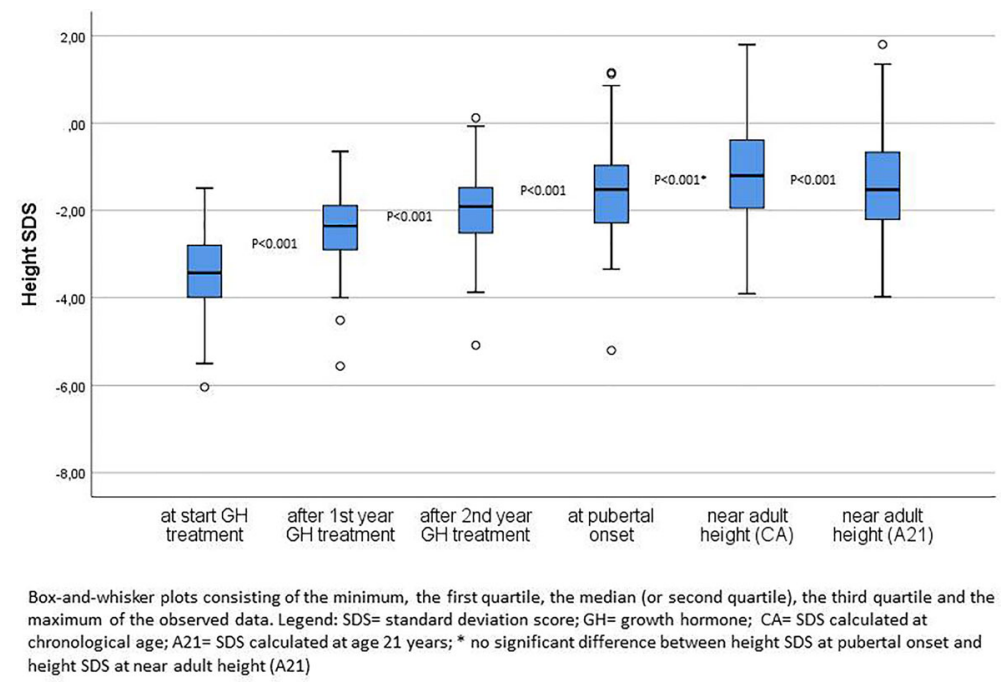

FIGURE 2 | Height SDS at start of GH treatment, after first and second years of GH treatment, at pubertal onset and near adult height.

\section{Prediction of a Poor Adult Height Outcome} ROC curve analysis was performed for $\Delta \mathrm{Ht}$ SDS after the first and second prepubertal years of $\mathrm{GH}$ treatment in relation to the studied poor final outcome parameters (total $\Delta \mathrm{Ht}$ SDS $<1, \mathrm{nAH}$ SDS $<-2$, and nAH SDS - MPH SDS $<-1.3)$. Only ROC-curves related to total $\Delta \mathrm{Ht}$ SDS $<1.0$ had an AUC $\geq 70 \%$ (varying between 78 and $82 \%$ ) and were further analyzed (Figure 3).

Tables 4A, B show the cut-off values for $\Delta \mathrm{Ht}$ SDS after 1 and 2 prepubertal years of GH treatment, with their sensitivity and specificity to predict total $\Delta \mathrm{Ht}$ SDS $<1.0$ (CA and A21). The sensitivity to predict total $\Delta \mathrm{Ht}$ SDS $<1.0$ (CA) with a specificity of $95 \%$ was 42 and $50 \%$, resulting in respectively $5 / 12(4.6 \%)$ and $6 /$ $12(5.5 \%)$ correctly identified poor final responders. At a $95 \%$ specificity level, 5/98 (4.5\%) of the good final responders were misclassified as poor responders. If the SDS was calculated on age 21 , the corresponding sensitivities were $33 \%$ after the first year and $44 \%$ after two years of GH treatment, giving respectively $6 /$ $18(5.4 \%$ and $8 / 18(7.2 \%)$ correctly diagnosed poor final responders. At a 95\% specificity level, 5/92 (4.2\%) of the good final responders were misclassified as poor responders. The ratio correctly diagnosed poor final responders/misclassified good final responders (1.0 at one year and 1.2 at two years) did not improve after two years of GH treatment.

As shown in Figure 1, eight of 12 patients with a total height increase of $<1$ (CA) had both a below median $\Delta \mathrm{Ht}$ SDS after one and at two years of treatment.

\section{DISCUSSION}

The first year response to $\mathrm{GH}$, in general represented as $\Delta \mathrm{Ht}$ SDS, is used by many clinicians to identify those children who may or may not benefit from long-term GH treatment. The first year response is also often used as a post hoc diagnostic criterion of GHD, especially in children with an idiopathic form of GHD. Although the first year response could be used to guide GH dosing, the current practice is to keep GH dosage stable over time on a body weight or body surface basis (in general between 0.25 and $35 \mu \mathrm{g} / \mathrm{kg}$.day) in GHD patients, at least in Belgium and several other European countries (12-14). While the first year growth response to GH is highly associated with the adult height outcome, it is a weak predictor for a poor growth outcome on an

TABLE 3 | Response to GH treatment in isolated GHD versus MPHD.

\begin{tabular}{|c|c|c|c|c|c|c|c|}
\hline & \multicolumn{3}{|c|}{ isolated GHD ( $n=66$ ) } & \multicolumn{3}{|c|}{ MPHD (n = 44) } & \multirow[b]{2}{*}{ p-value } \\
\hline & median & p25 & p75 & median & p25 & p75 & \\
\hline$\Delta \mathrm{Ht}$ SDS after 1 year $^{\mathrm{a}}$ & 1.04 & 0.66 & 1.36 & 1.02 & 0.61 & 1.59 & n.s. \\
\hline$\Delta \mathrm{Ht}$ SDS after 2 years $^{\mathrm{b}}$ & 1.40 & 1.07 & 1.99 & 1.47 & 0.82 & 2.07 & n.s. \\
\hline total $\Delta \mathrm{Ht}$ SDS $(\mathrm{CA})^{\mathrm{c}}$ & 2.14 & 1.59 & 2.97 & 2.04 & 1.53 & 3.20 & n.s. \\
\hline total $\Delta \mathrm{Ht}$ SDS $(\mathrm{A} 21)^{\mathrm{C}}$ & 1.88 & 1.20 & 2.69 & 1.81 & 1.14 & 2.79 & n.s. \\
\hline
\end{tabular}

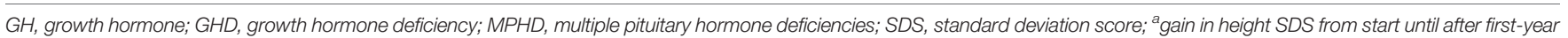

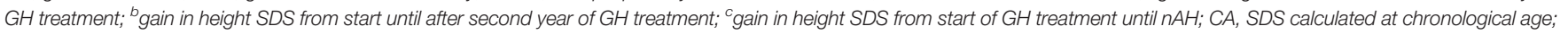
A21, SDS calculated at age 21 years; n.s., not significant. 
near adult height SDS calculated at chronological age

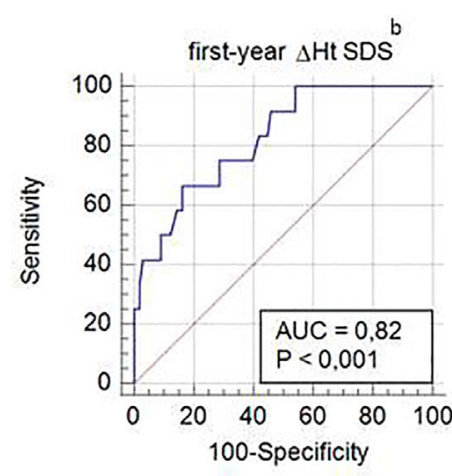

near adult height SDS calculated at age 21

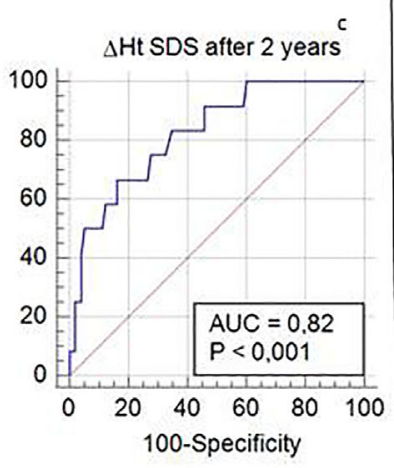

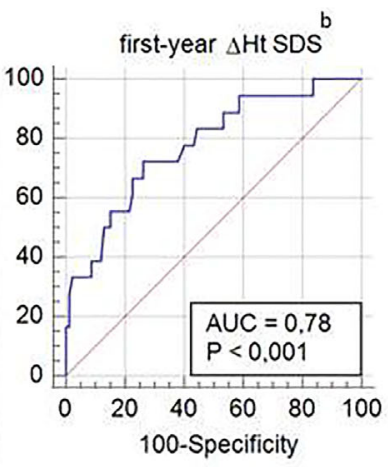

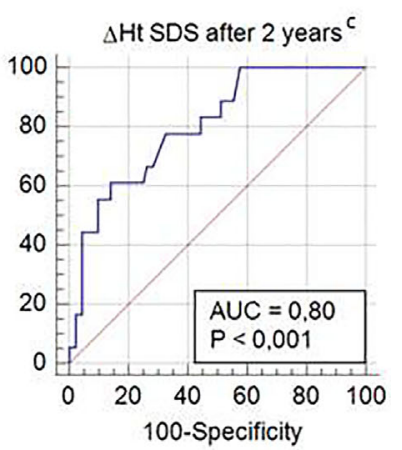

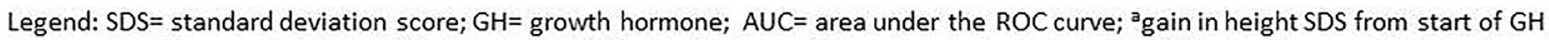

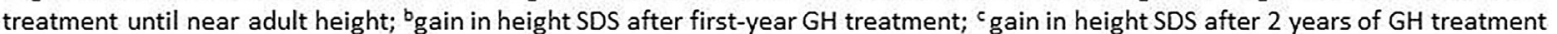

FIGURE 3 | ROC curve analysis for $\Delta$ height SDS after the first and second prepubertal GH treatment years, with its sensitivity and specificity to predict total $\Delta$ Ht SDS $<1$.

TABLE 4A | ROC curve analysis: cut-off values for $\Delta \mathrm{Ht}$ SDS after 1 and 2 years of prepubertal GH treatment, with its sensitivity and specificity to predict total $\Delta \mathrm{Ht}$ SDS $<1$ (A21).

\begin{tabular}{|c|c|c|c|c|c|}
\hline$\Delta \mathrm{Ht}$ after 1 year, $\mathrm{SDS}^{\mathrm{b}}$ & sensitivity (\%) & specificity (\%) & $\Delta \mathrm{Ht}$ after 2 years, SDS ${ }^{\mathrm{c}}$ & sensitivity (\%) & specificity (\%) \\
\hline 0.27 & 17 & 100 & 0.10 & 6 & 100 \\
\hline 0.47 & 33 & 95 & 0.72 & 44 & 95 \\
\hline 0.54 & 39 & 89 & 0.79 & 56 & 90 \\
\hline 1.22 & 94 & 41 & 1.65 & 94 & 43 \\
\hline 1.56 & 100 & 16 & 1.71 & 100 & 42 \\
\hline \multicolumn{3}{|c|}{$\begin{array}{c}\text { AUC: } 78 \%(95 \% \mathrm{Cl}: 69-85 \%) \\
n=110(P=18-\mathrm{G}=92)\end{array}$} & \multicolumn{3}{|c|}{$\begin{array}{c}\text { AUC: } 80 \%(95 \% \mathrm{Cl}: 72-87 \%) \\
n=110(P=18-\mathrm{G}=92)\end{array}$} \\
\hline
\end{tabular}

GH, growth hormone; AUC, area under the ROC curve; $\mathrm{Cl}$, confidence interval. ${ }^{a}$ gain in height SDS from start of GH treatment until near adult height; ${ }^{b}$ gain in height SDS after 1 year of GH treatment; ' gain in height SDS after 2 years of GH treatment; $A 21$, SDS calculated at age 21 years; $n$, number of patients; $P$, total $\Delta H t S D S<1$; $G$, total $\Delta H t S D S \geq 1$.

Bold: values at $95 \%$ specificity.

TABLE 4B | ROC curve analysis: cut-off values for $\Delta \mathrm{Ht}$ SDS after 1 and 2 years of prepubertal GH treatment, with its sensitivity and specificity to predict total $\Delta \mathrm{Ht}$ SDS $<1(\mathrm{CA})$.

\begin{tabular}{|c|c|c|c|c|c|}
\hline$\Delta \mathrm{Ht}$ after 1 year, $\mathrm{SDS}^{\mathrm{b}}$ & sensitivity (\%) & specificity (\%) & $\Delta \mathrm{Ht}$ after 2 years, SDS ${ }^{c}$ & sensitivity (\%) & specificity $(\%$ \\
\hline 0.27 & 25 & 100 & 0.10 & 8 & 100 \\
\hline 0.41 & 42 & 95 & 0.64 & 50 & 95 \\
\hline 0.53 & 50 & 91 & 0.79 & 58 & 88 \\
\hline 1.03 & 92 & 54 & 1.45 & 92 & 54 \\
\hline \multirow[t]{2}{*}{1.14} & 100 & 46 & 1.71 & 100 & 40 \\
\hline & $\begin{array}{l}(95 \% \mathrm{Cl}: 74-90 \% \\
(P=12-G=98)\end{array}$ & & & $\begin{array}{l}(95 \% \mathrm{Cl}: 74-89 \% \\
(P=12-G=98)\end{array}$ & \\
\hline
\end{tabular}

$\mathrm{GH}$, growth hormone; AUC, area under the ROC curve; $\mathrm{Cl}$, confidence interval. ${ }^{a}$ gain in height SDS from start of GH treatment until near adult height; ${ }^{b}$ gain in height SDS after 1 year of GH treatment; ' gain in height SDS after 2 years of GH treatment; CA, SDS calculated at chronological age; $n$, number of patients; $P$, total $\Delta H t S D S<1$; G, total $\Delta H t$ SDS $\geq 1$.

Bold: values at $95 \%$ specificity.

individual basis, as we previously reported in a cohort overlapping the cohort of this study (6). In this study, we investigated if a lower waning effect in the second year might compensate for a lower first year response in prepubertal children with GHD, translating in a better predictability of a poor total height gain after two years of GH treatment.
A waning effect was observed in the majority of the patients in our study: only $3.6 \%$ of the GHD patients had a second year $\Delta \mathrm{Ht}$ SDS that was higher than the first year $\Delta \mathrm{Ht}$ SDS. The waning effect was greater in those with a more impressive height gain in the first year, which occurred more often in younger patients, in patients with a more severe GHD, and a greater height deficit 
in relation to their parental height. These results are consistent with previous studies in prepubertal patients with $\operatorname{GHD}(15,16)$, with the exception of the absent association with the first year $\mathrm{GH}$ dose. The absent association with the GH dose in our study can be explained by the uniform dosing around $25 \mu \mathrm{g} / \mathrm{kg}$.day. However, previous attempts trying to overcome this waning effect in GHD patients by modifying the dose or the frequency of the GH regimen have not been very efficacious, as the dose response relationship diminishes during the second year $(17,18)$.

We confirmed that the majority of the height gain in $\mathrm{GH}$ treated GHD children occurs during the first 2 years of treatment (19). In our study, 69\% (CA) - 77\% (A21) of the total height gain was obtained in the first 2 years. We showed that there was still some improvement in the percentages of children obtaining a normal height or a height within the expected target range after two years of treatment.

Despite its important contribution to the total height gain, the height increase after two years of treatment did not greatly improve the sensitivity to predict a poor growth outcome at the end of treatment: the sensitivity to detect with $95 \%$ specificity a poor total height increase at the end of treatment increased from $42 \%$ after one year to only $50 \%$ after two years of treatment. This finding can be explained by our observation that the waning effect observed during the second treatment year is in general lower in patients with a below average first-year response than in patients with an above average first-year response, explaining the only moderate correlation between the first year growth response and second year growth response. In most studies, the best predictor of the second year growth response was the first year response $(16,20)$. However, we observed that about a third of the above median first year growth responders grow slower than the median during the second treatment year. This might be explained among other factors by a declining adherence (21).

Despite the $8 \%$ (CA) - 12\% (A21) increase in sensitivity for the second-year $\Delta \mathrm{Ht}$ SDS compared to first-year $\Delta \mathrm{Ht}$ SDS, the ratio correctly diagnosed poor final responders/misclassified good final responders did not change with a longer treatment duration due to the low (11-16\%) prevalence of poor final responders. We hypothesize that predictability of poor final outcome will be better in a cohort with a higher prevalence of poor growth response, e.g. children born small for gestational age without catch-up growth or Turner syndrome. To illustrate this argument, if the poor response rate would have been $30 \%$ in this cohort (33 poor responders and 77 good responders) we would have identified 16 poor responders (13.6\%) correctly and misclassified four good responders (3.6\%)(at $\mathrm{CA})$, a much better risk benefit ratio.

The patients remained short compared to their peers (mean nFAH SDS: -1.21 (CA) and -1.44 (A21) on Belgian references), but they almost reached their target height [nFAH minus $\mathrm{MPH}$ SDS: -0.19 (CA) and -0.43 (A21)]. This is consistent with other reports studying final height after GH treatment (19, 22-24).

This is the first study to evaluate the predictability of poor adult height outcome after two prepubertal GH treatment years in GHD children. This study has some shortcomings. Firstly, neither treatment adherence nor persistence of GHD was assessed routinely in the studied cohort. Secondly, the size of the cohort was rather small despite the national recruitment of patients. Near $\mathrm{AH}$ was taken as a proxy of $\mathrm{AH}$ as many patients usually stop $\mathrm{GH}$ treatment and disappear from follow-up when growth slows down to less than $2 \mathrm{~cm}$ per year and before $\mathrm{AH}$ is reached (25). To overcome this problem, nAH SDS could be calculated at a reference age of 21 years instead of the actual chronological age. This underestimates the real height SDS since most adolescents will still gain a few centimeters. On the other hand, since the mean height of the reference population also increases between 16 and 21 years, nAH SDS at the actual chronological age will overestimate the real height SDS. We therefore calculated nAH SDS both with age set at 21 years (worst case scenario) and at chronological age (best case scenario), accepting that the first method will underestimate and the second will overestimate the actual AH SDS.

In conclusion, the growth response after two prepubertal years of $\mathrm{GH}$ treatment did not meaningfully improve the prediction of poor near adult height outcome compared to the one year response. The decision to re-evaluate the diagnosis of GHD or adapt the GH dose in case of poor height response after 1 year should not be postponed for another year, as the prediction after two years has no added value in GHD children.

\section{DATA AVAILABILITY STATEMENT}

The raw data supporting the conclusions of this article will be made available by the authors, without undue reservation.

\section{ETHICS STATEMENT}

This study was approved by the ethical committee of Brussels Free University and the University Hospital Brussels in Belgium. All subjects gave written informed consent in accordance with the Declaration of Helsinki.

\section{AUTHOR CONTRIBUTIONS}

SS, RR, and JS contributed to the conception and design of the study. SS organized the database. SS performed the statistical analysis. SS wrote the first draft of the manuscript. SS, RR, and JS wrote sections of the manuscript. All authors contributed to the article and approved the submitted version.

\section{ACKNOWLEDGMENTS}

We would like to thank Franciska Verlinde, Christine Derycke, and Frédérique Schwilden for their help in data collection. In addition to the authors, the following investigators contributed to the Belgian Register for the Study of Growth and Puberty Problems: A. France, H. Dotremont, M. Den Brinker (University Hospital Antwerp), M. Cools, K. De Waele, M. Craen, S. Van Aken, S. van der Straaten (University Hospital Ghent), I. Gies, J. Vanbesien (University Hospital Brussels), J.P. Bourguignon, M.C. Lebrethon, A.S. Parent (University Hospital Liège), C. Heinrichs, S. Tenoutasse, C. 
Brachet, E. Boros (Hôpital Universitaire des Enfants Reine Fabiola, HUDERF, Brussels), M. Maes, V. Beauloye, P. Lysy (University Hospital Saint-Luc, Brussels), G. Massa, R. Zeevaert (Jessa Hospital, Hasselt), F. de Zegher, I. Francois, D. Beckers, M. Van Helvoirt, K. Casteels (University Hospital Leuven), D.

\section{REFERENCES}

1. Wit JM, Ranke MB, Albertsson-Wikland K, Carrascosa A, Rosenfeld RG, Van Buuren S, et al. Personalized Approach to Growth Hormone Treatment: Clinical Use of Growth Prediction Models. Horm Res Paediatr (2013) 79:25770. doi: 10.1159/000351025

2. Edward O WSC. Reiter, Growth Hormone Deficiency: Puberty and Final Height, Growth Hormone Therapy in Pediatrics - 20 Years of KIGS, Karger, Vol. pp. Karger (2007). pp. 136-44. doi: 10.1159/000101812

3. Bozzola M, Meazza C. Growth Hormone Deficiency: Diagnosis And Therapy In Children. Expert Rev Endocrinol Metab (2010) 5:273-84. doi: 10.1586/ eem.09.69

4. Bang P, Ahmed SF, Argente J, Backeljauw P, Bettendorf M, Bona G, et al. Identification And Management Of Poor Response To Growth-Promoting Therapy In Children With Short Stature. Clin Endocrinol (Oxf) (2012) 77:169-81. doi: 10.1111/j.1365-2265.2012.04420.x

5. Straetemans S, Thomas M, Craen M, Rooman R, De Schepper J. Poor Growth Response During The First Year Of Growth Hormone Treatment In Short Prepubertal Children With Growth Hormone Deficiency And Born Small For Gestational Age: A Comparison Of Different Criteria. Int J Pediatr Endocrinol (2018) 2018:9. doi: 10.1186/s13633-018-0064-3

6. Straetemans S, De Schepper J, Thomas M, Tenoutasse S, Beauloye V, Rooman R. Criteria for First-Year Growth Response to Growth Hormone Treatment in Prepubertal Children With Growth Hormone Deficiency: Do They Predict Poor Adult Height Outcome? Front Endocrinol (2019) 10:792. doi: 10.3389/ fendo.2019.00792

7. Acerini CL, Wac K, Bang P, Lehwalder D. Optimizing Patient Management and Adherence for Children Receiving Growth Hormone. Front Endocrinol (2017) 8:313. doi: 10.3389/fendo.2017.00313

8. Ranke MB. The Kabi Pharmacia International Growth Study: Aetiology Classification List With Comments. Acta Paediatr Scand Suppl (1991) 379:87-92. doi: 10.1111/j.1651-2227.1991.tb12052.x

9. Niklasson A, Ericson A, Fryer JG, Karlberg J, Lawrence C, Karlberg P. Acta Paediatr Scand (1991) 80:756-62. doi: 10.1111/j.1651-2227.1991.tb11945.x

10. Cole TJ. Some Questions About How Growth Standards Are Used. Horm Res (1996) 45 Suppl 2:18-23. doi: 10.1159/000184843

11. Roelants M, Hauspie R, Hoppenbrouwers K. References For Growth And Pubertal Development From Birth To 21 Years In Flanders, Belgium. Ann Hum Biol (2009) 36:680-94. doi: 10.3109/03014460903049074

12. Ross J, Lee PA, Gut R, Germak J. Factors Influencing The One- And Two-Year Growth Response In Children Treated With Growth Hormone: Analysis From An Observational Study. Int J Pediatr Endocrinol (2010) 2010:494656. doi: 10.1186/1687-9856-2010-494656

13. Zantleifer D, Awadalla S, Brauner R. Growth Response To Growth Hormone During The First Year As A Diagnosis Criterion Of Growth Hormone Deficiency. Horm Res (1993) 40:123-7. doi: 10.1159/000183780

14. Kriström. The First-Year Growth Response To Growth Hormone Treatment Predicts The Long-Term Prepubertal Growth Response In Children. BMC Med Inf Decision Making (2009) 9:1-10. doi: 10.1186/1472-6947-9-1

15. Ranke MB, Guilbaud O. Growth Response in Prepubertal Children With Idiopathic Growth Hormone Deficiency During the First Two Years of Treatment With Human Growth Hormone. Analysis of the Kabi Pharmacia International Growth Study. Acta Paediatr Scand Suppl (1991) 379:109-15:discussion 116. doi: 10.1111/j.1651-2227.1991. tb12060.x
Beckers, T. Mouraux (CHU UCL Mont Godinne), K. Logghe (Delta Hospital Roeselare), O. Chivu (CHC Espérance, Montegnée), S. Depoorter (AZ St. Jan Brugge). This study was supported by a research grant from the BElgian Society for PEdiatric Endocrinology and Diabetology (BESPEED).

16. Ranke MB, Lindberg A, Chatelain P, Wilton P, Cutfield W, AlbertssonWikland $\mathrm{K}$, et al. Derivation and Validation of a Mathematical Model for Predicting the Response to Exogenous Recombinant Human Growth Hormone (gh) in Prepubertal Children With Idiopathic gh Deficiency. Kigs International Board. Kabi Pharmacia International Growth Study. J Clin Endocrinol Metab (1999) 84:1174-83. doi: 10.1210/jcem.84.4.5634

17. Hakeem V, Hindmarsh PC, Brook CG. Intermittent Versus Continuous Administration Of Growth Hormone Treatment. Arch Dis Child (1993) 68:783-4. doi: 10.1136/adc.68.6.783

18. Yokoya S, Araki K, Igarashi Y, Kohno H, Nishi Y, Hasegawa Y, et al. High-Dose Growth Hormone (Gh) Treatment In Prepubertal Gh-Deficient Children. Acta Paediatr Suppl (1999) 88:76-9. doi: 10.1111/j.1651-2227.1999.tb14357.x

19. Carel JC, Ecosse E, Nicolino M, Tauber M, Leger J, Cabrol S, et al. Adult Height After Long Term Treatment With Recombinant Growth Hormone For Idiopathic Isolated Growth Hormone Deficiency: Observational Follow Up Study Of The French Population Based Registry. BMJ (2002) 325:70. doi: 10.1136/bmj.325.7355.70

20. Cole TJ, Hindmarsh PC, Dunger DB. Growth Hormone (Gh) Provocation Tests And The Response To Gh Treatment In Gh Deficiency. Arch Dis Child (2004) 89:1024-7.

21. de Arriba Muñoz A, Muñiz VC, Saez JJA, Beisti A, Llovet E, Aizpún JIL. Impact of Adherence on Growth Response During the First 2 Years of Growth Hormone Treatment. Endocrine (2020) 72(2):513-23. doi: 10.1007/s12020020-02560-6

22. Rachmiel M, Rota V, Atenafu E, Daneman D, Hamilton J. Final Height in Children With Idiopathic Growth Hormone Deficiency Treated With A Fixed Dose of Recombinant Growth Hormone. Horm Res (2007) 68:236-43. doi: 10.1159/000101427

23. Blethen SL, Baptista J, Kuntze J, Foley T, LaFranchi S, Johanson A. Adult Height in Growth Hormone (Gh)-Deficient Children Treated With Biosynthetic Gh. The Genentech Growth Study Group. J Clin Endocrinol Metab (1997) 82:418-20. doi: 10.1210/jcem.82.2.3734

24. Cutfield W, Lindberg A, Albertsson Wikland K, Chatelain P, Ranke MB, Wilton P. Final Height In Idiopathic Growth Hormone Deficiency: The Kigs Experience. KIGS Int Board Acta Paediatr Suppl (1999) pp:72-5. doi: 10.1111/ j.1651-2227.1999.tb14356.x

25. Frindik JP, Baptista J. Adult Height In Growth Hormone Deficiency: Historical Perspective And Examples From The National Cooperative Growth Study. Pediatrics (1999) 104:1000-4.

Conflict of Interest: Author RR was employed by company Pendocon bv. RR has received consulting fees from Pfizer and Ferring and is a member of the Pfizer iGRO Advisory Board.

The remaining authors declare that the research was conducted in the absence of any commercial or financial relationships that could be construed as a potential conflict of interest.

Copyright (c) 2021 Straetemans, Rooman and De Schepper. This is an open-access article distributed under the terms of the Creative Commons Attribution License (CC BY). The use, distribution or reproduction in other forums is permitted, provided the original author(s) and the copyright owner(s) are credited and that the original publication in this journal is cited, in accordance with accepted academic practice. No use, distribution or reproduction is permitted which does not comply with these terms. 